\title{
Assessment of the Socia-Economic Benefits of Two Indigenous Fruit Tree: Apple (Gornoaltaiskoje) and Sea Buckthorn (Altaja) to the People of Biger Rural City in Western Region of Mongolia
}

\author{
Gunjargal Balt', Xiaoqian Chen1, Suvdantsetseg Balt ${ }^{2,3}$ \\ ${ }^{1}$ Forestry Economics and Management, Beijing Forestry University, Beijing, China \\ ${ }^{2}$ Department of Economic Research Sector, Institute for Strategic Studies, Ulaanbaatar, Mongolia \\ ${ }^{3}$ Laboratory for Remote Sensing and Space Science, National University of Mongolia, Ulaanbaatar, Mongolia \\ Email: gungee09@yahoo.com,xiaoqian.chen@efi.int, suvdantsetseg@issmon.mn, \\ suvd16@num.edu.mn,suvd16@yahoo.com
}

Received 20 April 2016; accepted 21 May 2016; published 26 May 2016

Copyright (C) 2016 by authors and OALib.

This work is licensed under the Creative Commons Attribution International License (CC BY).

http://creativecommons.org/licenses/by/4.0/

(c) (i) Open Access

\begin{abstract}
The purpose of this research is to assess the socio-economic importance of two indigenous fruit trees of Apple and Sea buckthorn in Biger rural city of Gobi-Altai province, Mongolia. Specifically, the study assesses the contributions of indigenous fruits to household's cash income and to supply the local fruits demand. This study used a qualitative and quantitative analyzing approach which conducted field survey using semi-structured interview with locals and experts, observation and self-designed household exploratory questionnaires were used for primary data collection. The result of research found 12.5 hectare area at 3 places in Biger city planting small apple and sea buckthorn and they were planning to extent the planting area in another 15 hectare from 2015. These two fruits have been supplied big benefits to the 124 householders cash income, domestic use of bordering 17,822 citizens apple's demand and supply of primary goods for local wine industry since 1971. The other benefits of the fruits planting area also have been supplying 1726 ton forage for $\mathbf{4 0 4}$ herder householder's livestock food demand in the case area. The local small afro farm areas are contributing lots of benefits to the local householders' livelihood and wellbeing, neighboring citizens' fruit demand, livestock forage supply and also reducing desertification process in the Gobi desert region of Mongolia which is very important forest type.
\end{abstract}

\section{Keywords}

Indigenous Fruit Trees, Fruit Demand, Cash Income, Rural Households

How to cite this paper: Balt, G., Chen, X.Q. and Balt, S. (2016) Assessment of the Socia-Economic Benefits of Two Indigenous Fruit Tree: Apple (Gornoaltaiskoje) and Sea Buckthorn (Altaja) to the People of Biger Rural City in Western Region of Mongolia. Open Access Library Journal, 3: e2671. http://dx.doi.org/10.4236/oalib.1102671 


\section{Subject Areas: Agricultural Science, Economic System, Socioeconomics}

\section{Introduction}

Mongolia is a land locked country which locates in central Asia. Mongolian territory is divided into three main categories of ecological zones of forest, steppe, and Gobi-desert [1]. The case area of this research locates in the western region and Gobi-desert ecological zones of Mongolia. Mongolia has a vast tradition of the wild fruit utilization. Mongolia used up a wild berries for a medicines, drinks (a tea, juice, and a wine) and for a decoration too except for food [2]. These species are more used for common life usage and moreover traditional medicines, industry products of juice, wine and tea products. Since 1954, Mongolian scientific research centers have studied cultivation technologies of fruits of small apple, blackcurrant, sea buckthorn and raspberry, improvement in cropping technologies and practices of fruits [3]. No more researchers studied its social and economic benefits.

Human activity based crop farmer system is not well developed in Gobi region of Mongolia. The Biger city of Gobi-Altai province was established the complex crop farmer system including fruits cultivation, fodder and hay preparation and vegetables areas in 1962 which have been giving big social and economic benefits to the local economy [4]. However, after the economic market civilization, the size of the cultivation area decreased, and some types of fruits disappeared, and crop management was changed that was giving negative impact on social and economic supports. Nowadays, very few of local farmers are cultivating vegetables for daily consumption such as potato, carrot, onion, beetroot, cabbage, and various of cereals for traditional flour food such as corn, wheat, barley, oats, and silage crops, and fodder crops for supply livestock's production as well as grain, special fruits of small apple, crab apple, winter sort apple, and replanting a sea buckthorn and currant berry for local wine drinking industry.

\section{Methodology}

This study used a qualitative (document review, interview) and quantitative analyzing approaches to analyzing data sets and used the "participatory inventory" approach for primary data collection [5] [6]. We conducted document review from the study findings derived from other researchers.

The data collection step is captured the local information for the socio-economic and other benefits of agro farm land in the local area [7]. This research is essentially the first about socio-economic benefits of fruits in the study area. Thus detailed information cannot be obtained from previous studies and reports. Therefore, we collect information by using necessary instruments of self-administrated questionnaires, face-to-face interviews, and group discussion workshop as well as collecting statistical data from local area using local's participation [8].

The questionnaire consisted 28 questions which mostly asked about household condition, economic source, farming activity, agro farm types, social benefits, ecological benefits, Harvesting and cultivating size, product user, price, market mechanism, and indigenous fruit tree income so on. The questionnaire answer is easy to tick and choose the best option and shortly answer by word in some questions.

Simple random sampling was used to select householders for the questionnaire from all householders of Biger soum. The main requirements for the respondent are who have agro farm land, herder, fruits customer, and only one person from household who should know wells about household and local conditions.

The interview process was taken about 25 minutes with interviewers that we had prepared questions and free talking to get more information. The questions are almost same as self-administrated questionnaire. The interview had same requirements with questionnaire. The selection process of the interviewer was selected the simple householders in the city who have linked with farm activities from 1962. The main objective of the interview was to observe their attitude, emotion, character, self-confidence, and more face-face explanation about their satisfaction on farm activity and its importance for their livelihood. The field survey of questionnaire and interview was undertaken from 20 January to 28 February to 2016.

In addition, we were also done the physical observation of photo covering, cultivation process, selling mechanisms in order to see local's perspective and have a clue on the socio-economic impact of indigenous fruit trees in the study area in 25 July to 14 August 2015. During this time, we also organized group discussion 1 time to 
use locals' potential participation and their valuable knowledge in order to identify their needs, local problems related to crop farmer development, fruits cultivation, socio- economic benefits, local advantages and desertification process.

The official statistical data collection and qualitative information was initiated through interviews with local government authorities, agriculture development officers and local statistic center in the area.

After collected data we inputted raw data into Microsoft Excel 2010 software to do analysis. The data obtained from all the sources were evaluated using content analysis, descriptive statistics and graphs.

\section{Description of the Study Area}

Why we selected the case area for this research is very special case that planting two types of fruits trees in the Gobi area and also that giving big benefit to the local residents and industry. This novelty of the research is planned actions representatives in Gobi regions of country for the first time of forestation work done to provide social and economic benefits of planting forests that may be compared with the amount of permitted.

The Biger city is situated in the Gobi-Altai province, at south western of Mongolia that is largely remoteness area from centralization of economic and population centres see Figure 1. There are 5 villages (Bag in Mongolian) namely 1, 2, 3, 4, and 5 governed by this city. Biger region covers an area of 3730 square kilometres, sheltering 2249 inhabitants (male 1143, female 1106), 635 stakeholders, and 91,700 numbers of livestock. 24\% percent of the population is living in the town centre where residents work in the offices whilst most of the residents are involved in the pastoral herding industry in neighboring centre and in the remote area, providing the main local employment and livelihoods for local economy [9] [10].

The altitudinal range is between 1300 and $3750 \mathrm{~m}$ above sea level. There are several major majestic peaks of Mongol Altai and Khukh Serkh mountains stretch exceeds $3000 \mathrm{~m}$. The local climate is characterized as continental harsh, semi-arid, and salty. Summer annual average air temperature is about $25^{\circ} \mathrm{C}$, sand surface temperature is $45^{\circ} \mathrm{C}-60^{\circ} \mathrm{C}$, annual precipitation is $72.6 \mathrm{~mm}$, and sunshine is 3103 hours/year [4].

\section{Results}

We collected totally 40 questionnaires from random respondents who represented the householders. The over

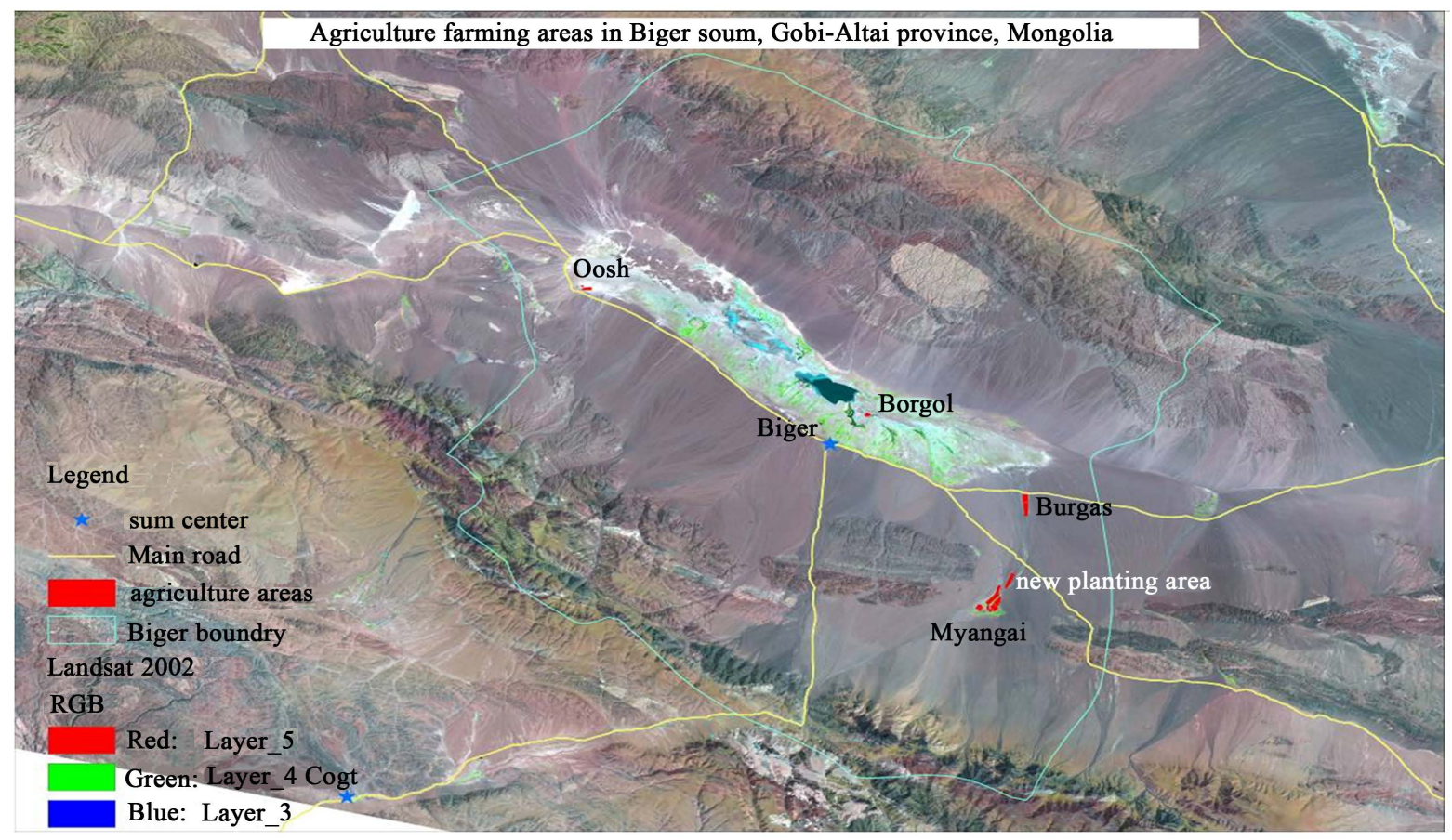

Figure 1. The location of the study area at Biger city, western Mongolia. 
$74 \%$ of the total respondents were 30 - 50 aged people where $25 \%$ females and $75 \%$ males. The 32 of total respondents are earning cash income from fruit industry and 8 respondents are customers. If we are more clearly see them that 32 householders earn cash income from apple fruits and 19 householders earn cash income from both sea buckthorn and apple.

The $80 \%$ of the respondents are working in herding industry combined with agriculture farmer and $20 \%$ office workers combined with farmer. But these $20 \%$ of families are not earn income and just using apple fruit for their own use. Figure 2 is showing the main income sources of the total respondents.

The local fruit farmers are packaging small apple into 1 package of $50 \mathrm{~kg}$ for sale. The total number of fruit farming householders are 124 at the Biger city where the householders who collecting apple fruits less than 2 packages that are not considered to sell out just using for family use. All householders are harvesting in different planting size and collecting different amount of apple fruits. Figure 3 is presenting the householders average cash income from small apple. The small apple is sold $50 \$$ per 1 package of $50 \mathrm{~kg}$.

The other factor is sea buckthorn that is bit higher product than small apple. They are selling the sea buckthorn in 4 US dollar per $1 \mathrm{~kg}$ to the local wine industry. The house holder are harvesting different amount of sea buckthorn ranging from $800 \mathrm{~kg}$ to 3 ton.

As my random questionnaire 19 householders are planting the sea buckthorn in different sizes of area range. The average income from sea buckthorn is 3413.2US per year for the respondents of case area.

The other benefit of the farming area is supplying 1726 ton forage for 404 herder householder's livestock food demand in the case area and also few of neighboring herders. The householders are preparing hay forage in 5 - 30 hectare areas and preparing different amount of forage from hay farming area for their livestock. The preparing amount of forage is increasing at the case area since 2002 (Figure 4).

Social benefits: Social-economic changes have been observed from research experience and observation. The social benefit of the agro farm land was invaluable in the case area. There are observed many cultural activities and social events organized during cultivation and harvesting period such as fruits and vegetables exhibition and show, local farm day, agro farm small training, afro and ecotourism for local and international people and information exchange activity on experience sharing. Table 1 shows the other social and luxury benefits of the agro farm land and indigenous fruit's selling. The types of benefits are different for the householders that indicated basic indicators (food, clothes, and groceries), paying school fees and buying luxuries, social networking, training, knowledge sharing, desertification reducing, livestock farming and supporting nomadic culture development.

$95.8 \%$ of the household respondents reported that the indigenous fruit's contribute to local fruits demand and $4.2 \%$ of the respondents are not said that is not good enough for the local fruits demand.

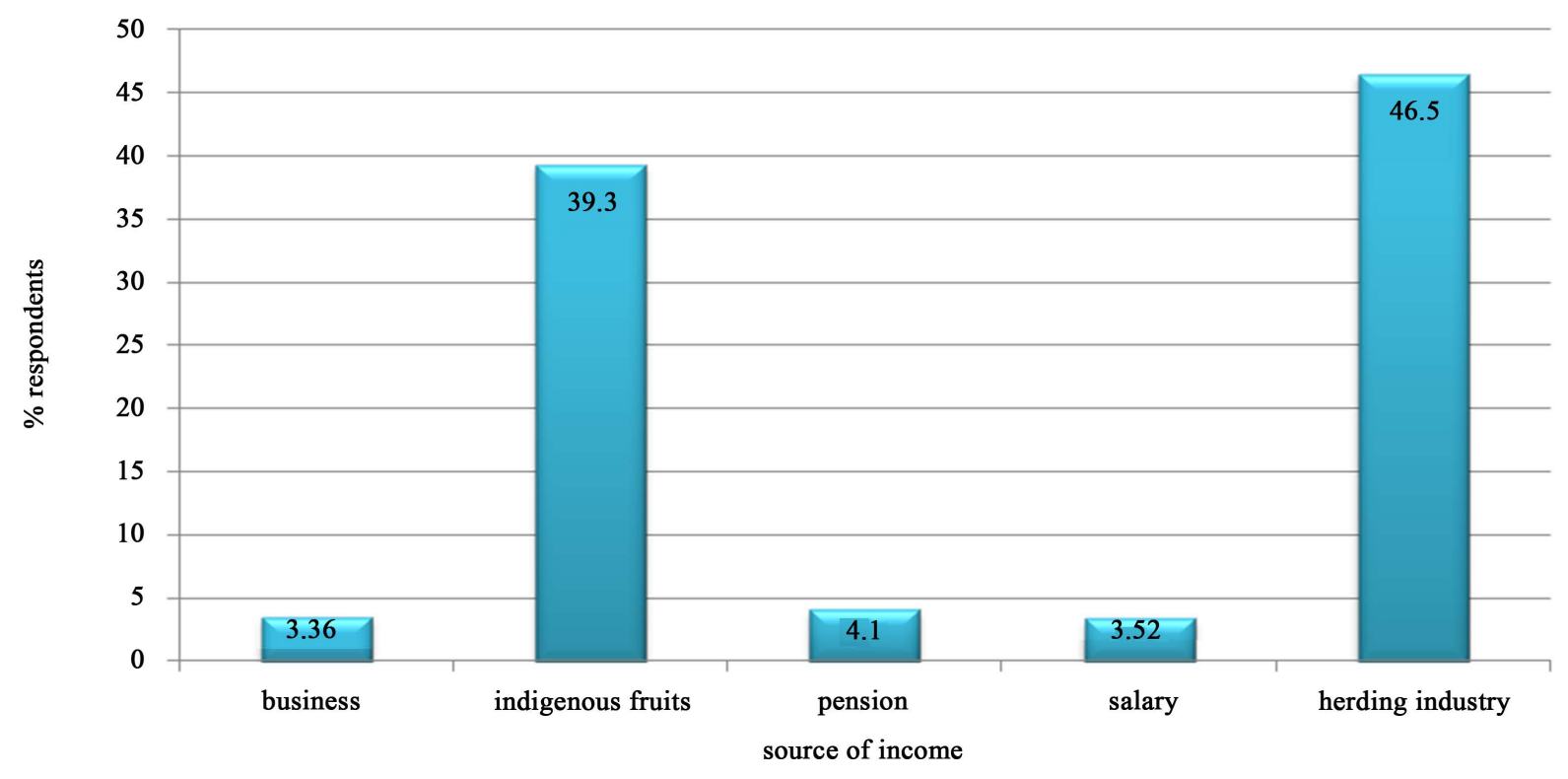

Figure 2. The main income sources of the respondents. 


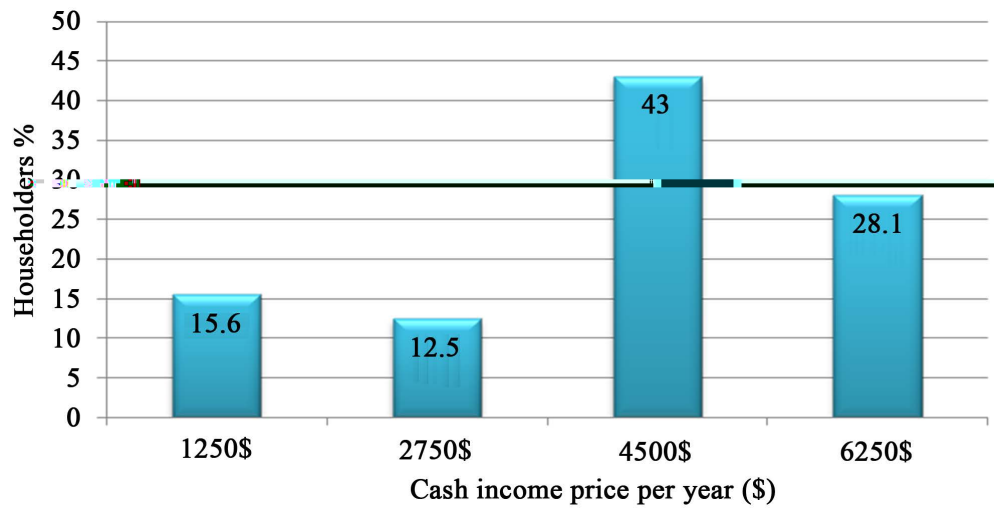

Figure 3. The householder cash income from small apple per year.

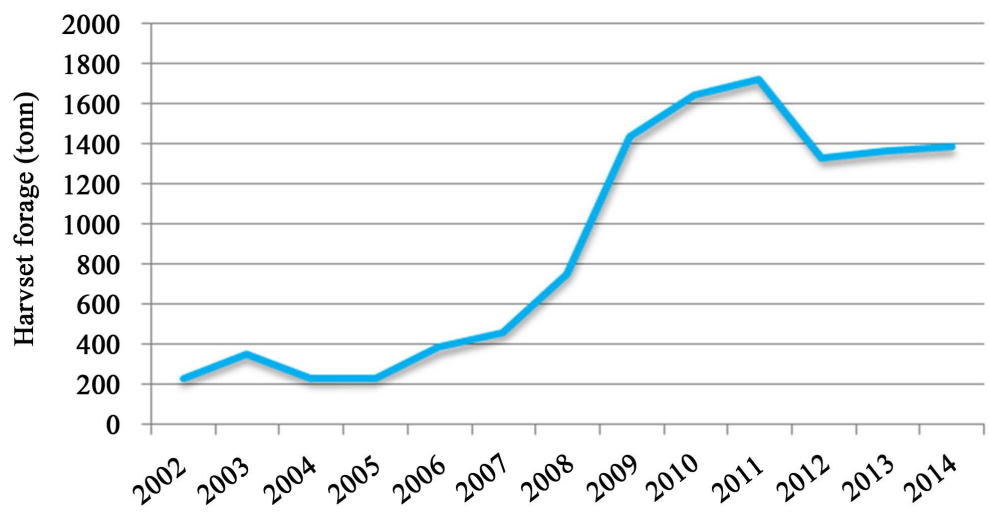

Figure 4. Harvested forage (tonn) in Biger city, Mongolia.

Table 1. Indicators of benefits from the agro farm land.

\begin{tabular}{cc}
\hline Types of benefits & Respondents by percent \\
\hline Basic needs e.g. food clothes and groceries & 44.1 \\
School fee & 19.2 \\
Luxury & 6.1 \\
$\begin{array}{c}\text { More than one benefits e.g. purchasing of livestock, machine cart, } \\
\text { transport money, house maintenance and needs }\end{array}$ & 29.3 \\
\hline
\end{tabular}

\section{Discussion}

Indigenous fruits trees have been played big role for livelihood and ecological conservation process of the case area. Apple and Sea buckthorn fruits are generating big cash income and support for the local farm communities of Biger citizens in the western Mongolia. The result of the study is show that people depend on indigenous fruits as the major source of their income. The most of the farmers are combining the agro farm activity with herding farm activity. The respondents pointed out that the income generated from the indigenous fruits is their major source of income because the fruits can be used for all householders fruit demand in the local area. These results explain the importance of indigenous fruits to rural households.

The price of the Sea Buckthorn is determined based on the size. The price is ranging average $4 \$$ of price per for $1 \mathrm{~kg}$. The price for Apple ranges average price $50 \$$ per 1 package for $50 \mathrm{~kg}$. The agro farm householders are averagely collect about 25 package of apple and 9000 kilogram of sea buckthorn a per year which is much help for their livelihood during summer period. Both fruits are popular but apple fruits are more valuable mainly in terms of cash income while Sea Buckthorn fruits are most valuable on both cash income and food. 
Apple fruit is supplying food requirements especially during poor harvesting years. The average cash income from apple is $4310 \$$ per year in per householder. In contrast, the average cash income from Sea buckthorn is $3413 \$$ per year in per householder. The both of fruits species are positively contribute to the household cash income. The majority of the respondents stated that selling process and places of the fruits in the local area is not compatible. Because they are selling it in the main road, Biger open market, and give to local wine industry. They would like to increase the agro farm area by increasing number and types of fruits then want to sell it in the big market and population centers. When they are selling fruits in urban areas, the price will be higher than recent cost. The low price in the study area is attributed to high competition for the customers but not good for sellers.

The fruits of Apple are mainly sold in the homestead and local markets and the fruits are mostly preferred by rural people within the region. The result indicate that indigenous fruit tree products are source of food and also a means of generating cash income essential for purchasing the required households goods in rural areas. Most of the households in Myangai village generate cash income from indigenous fruits for household needs.

The study results showed majority of the households obtain more than one benefit from the sale of indigenous fruits and generating cash income essential for purchasing the required households goods. These benefits include school fees for their children and pay hospital bills for family members. One respondent reported that they are living a luxury life after selling indigenous fruits, for instance they managed to buy a Digital Satellite Television (DSTV), freezer, new house and machine cart for his household. This indicates the importance of the contribution of indigenous fruit trees towards rural households' well- being.

In the Biger city of Mongolia, the local customers have been used indigenous fruits as a part of their natural food resource that can supply their fruits demand during the periods of food shortages and poor harvesting years. The utilization of indigenous local farm land is providing the not only fruits sources but also supply livestock forage and other vegetable supply. Moreover it is contributing to grassland conservation and interest of local people at their home land.

\section{Conclusions}

The study assessed the socio economic importance of agro farm land especially the two types of indigenous fruits which is very important role for the local economic development and ecological conservation in the Biger city of Gobi-Altai province and western desert area of Mongolia.

The result indicates that Apple is mainly valued for its contribution to households' cash income and Sea buckthorn is valued as a food source and industry supply. The cash income generated from the sale of the indigenous fruits is essential for purchasing the required households goods. Majority of the households feel that the cash incomes generated from the sale of indigenous fruits are sufficient enough to sustain household family members. However, the entire sample population has experienced a positive change in their livelihood and life style since the sale of the indigenous fruits.

This study concludes that Apple and Sea buckthorn indigenous fruits are important source of cash income for the local farm householders, good social and education networking place for the local and international people, good experience of small apple and sea buckthorn agro farm in Gobi-desert area, source of forage for the herder families, compatible living condition for the local communities and supply of fruit demand in the Gobi-region's customers.

Therefore, we need to study more its social-economic benefits and also ecological benefits of the agro farm land need to be studied more in future work related with climate change adaptation and human activity.

\section{References}

[1] Tsogbaatar, J. (2004) Forest Rehabilitation in Mongolia, Extent of Forests. Geo-Ecology Institute of the Mongolia Academy of Science, Ulaanbaatar.

[2] Munkhzorig, D., Officer of Ministry of Nature and Environment (2005) Report on National Forest and Water Policy of Mongolia, Current Situation of Forest Resources and the Forestry Sector. Ulaanbaatar.

[3] Altansukh, N. (1996) Country Report to the FAO International Technical Conference on Plant Genetic Resources. Chapter 5, Mongolia Country Report, Ulaanbaatar.

[4] Suvdantsetseg, B., Fukui, H. and Tsolmon, R. (2010) Ecotourism Development Planning in the Biger Soum of Gobi-Altai Province, Mongolia. The 4th Annual International Conference on the Application and Development of Geos- 
patial Technologies in Mongolia, Ulaanbaatar, 21-23 June 2010, 153-158.

[5] (2015) Socio-Economic Importance of Two Indigenous Fruit Trees: Strychnos Cocculoides and Schinziophyton Rautanenii to the People of Rundu Rural West Constituency in Namibia. Article, Selma Elago Stellenbosch University.

[6] Dagmar, M. (2004) Economics of Indigenous Fruits Tree Crops in Zimbabwe. University of Hannover, Hannover.

[7] Amgalanbaatar, O. (2015) Apple Cultivation Possibility and Condition at Gobi-Altai Province. Conference Proceedings of the Future of Altai Region and Gateway of Science-Based Development in Gobi-Altai Province, Mongolia, 28 May 2015, 13-16.

[8] Erdenebaatar, B. and Humphrey, C. (1996) Socio-Economic Aspects of the Pastoral Movement Patterns of Mongolian Herders. In: Humphrey, C. and Sneath, D., Eds., Culture and Environment in Inner Asia. Vol. 1: The Pastoral Economy and the Environment, 1996, 58-110.

[9] Suvdantsetseg, B., Fukui, H. and Purevdorj, G. (2010) Inventory of the Soil Properties for Sanatorium Treatment: Case Study of Five Sand Sanatorium, Mongolia. Journal of Medical Association of Mongolia, 47, 19-23.

[10] Suvdantsetseg, B., Fukui, H. and Oe, M. (2012) Evaluation of Ecotourism Resources through Participatory Geo-Spatial Approach: A Case of the Biger City, Mongolia. ASEAN Journal on Hospitality and Tourism, 10, 162-176. 